\title{
Mass loss and nutrient dynamics during litter decomposition under three mixing treatments in a typical steppe in Inner Mongolia
}

Yulian Tan ${ }^{1,2}$, Jin Chen ${ }^{3}$, Liming Yan ${ }^{1,4}$, Jianhui Huang ${ }^{1 *}$, Lixin Wang ${ }^{5,6}$, Shiping Chen ${ }^{1}$

${ }^{1}$ State Key Laboratory of Vegetation and Environmental Change, Institute of Botany, Chinese Academy of Sciences, Beijing 100093, China

${ }^{2}$ Graduate University of Chinese Academy of Sciences, Beijing 100049, China

${ }^{3}$ Ezhou Environmental Monitoring Station, Ezhou 436000, China

${ }^{4}$ School of Life Sciences, Fudan University, Shanghai 200433, China

${ }^{5}$ Department of Earth Sciences, Indiana University-Purdue University, Indianapolis (IUPUI), Indianapolis, Indiana 46202, USA

${ }^{6}$ Water Research Center, School of Civil and Environmental Engineering, University of New South Wales, Sydney, NSW 2052, Australia

\section{*Corresponding author:}

Jianhui Huang, Ph.D.

State Key Laboratory of Vegetation and Environmental Change

Institute of Botany, Chinese Academy of Sciences

No. 20 Nanxincun, Xiangshan,

Beijing, 100093, China

Tel: 86-10-62836279, Fax: 86-10-62599059

Email: jhhuang@ibcas.ac.cn

This is the author's manuscript of the article published in final edited form as:

Tan, Y., Chen, J., Yan, L., Huang, J., Wang, L., \& Chen, S. (2013). Mass loss and nutrient dynamics during litter decomposition under three mixing treatments in a typical steppe in Inner Mongolia. Plant and soil, 366(1-2), 107-118.

http://dx.doi.org/10.1007/s11104-012-1401-6 


\begin{abstract}
Background and Aims: Mixing effects during litter decomposition could occur
\end{abstract} between two or more different litter species because of the potential nutrient transfer. However, evidence of mixing effects is variable and the underlying mechanisms remain unclear. Using a three-year decomposition experiment, we aim to examine the effects of litter mixing and position on decomposition rates and nitrogen $(\mathrm{N})$ and phosphorus $(\mathrm{P})$ dynamics.

Methods: We studied litter decomposition of Stipa krylovii (Sk) and Astragalus galactites (Ag), two dominant species with contrasting litter quality in a typical steppe of northern China in single decomposition and three mixing treatments. The three mixing treatments included thorough mixing (Sk-Ag), Ag over Sk (Ag/Sk), and Sk over $\mathrm{Ag}(\mathrm{Sk} / \mathrm{Ag})$.

Results: Both the Sk-Ag and the Sk/Ag mixture had negative mixing effects on the mass loss of the litter mixture, while the Ag/Sk mixture had a neutral mixing effect. The percent mass loss was higher when the litter species was placed at the top ( $25.0 \%$ and $51.9 \%$ of mass remaining for $\mathrm{Ag}$ and $\mathrm{Sk}$ ) than at the bottom (38.3\% and $61.8 \%$ of mass remaining for Ag and Sk). The Sk/Ag mixture had negative effects on the release of $\mathrm{N}$ while all three mixing treatments had positive effects on the release of $\mathrm{P}$.

Conclusions: Our results indicate that: (1) mixing treatments can induce different mixing effects; (2) environmental factors likely play an important role in controlling the mixing effect; (3) litter-mixtures have different non-additive effects on $\mathrm{N}$ and $\mathrm{P}$, which may further increase the heterogeneity of $\mathrm{N}$ and $\mathrm{P}$ availability as the two litter species may fall differentially in terms of space and time.

Keywords: Litter decomposition, mixing effects, mass loss, nitrogen release, phosphorus release 


\section{Introduction}

In most terrestrial ecosystems, litter decomposition is a fundamental ecological process that provides soil nutrients for plant biological activity (Swift et al. 1979). Due to its importance in nutrient cycling, the dynamics of plant litter decomposition and the controlling factors have been the focus of a considerable number of studies. Previous studies have revealed that litter decomposition could be affected by a series of abiotic factors, such as precipitation (Austin and Vitousek 2000), UV-radiation (Austin and Vivanco 2006), water table depth (Moore et al. 2007), and soil nutrient availability (Dent et al. 2006; Hobbie and Vitousek 2000). In addition, biotic factors, such as litter quality (Berg and Ekbohm 1991), soil animals (Bradford et al. 2002), and soil microbes (Daniel and Anderson 1992) could have great impact on litter decomposition. In semiarid environments, litter decomposition is more complex and additional factors such as vegetation structure and soil moisture could also play important roles (e.g., Throop and Archer 2009; Wang et al. 2009). Among these factors, it is often believed that litter quality, i.e., nitrogen $(\mathrm{N})$ content, $\mathrm{C} / \mathrm{N}$ ratio and lignin/ $\mathrm{N}$ ratio, is the most important factor in determining the rate of litter decomposition especially in a terrestrial ecosystem (Aerts 1997; Vivanco and Austin 2006).

Most of the previous studies, however, have only focused on the decomposition of single litter species, while litter layer in natural ecosystems is in fact a mixture of different plant species. Decomposition of one litter species is inevitably influenced by the presence of adjacent litter species, resulting in so-called mixing effects which may either facilitate or inhibit the rate of overall litter decomposition (Jonsson and Wardle 2008; McTiernan et al. 1997; Wardle et al. 1997). Such mixing effects can also be regulated by environmental factors (Gartner and Cardon 2006; Madritch and 
Cardinale 2007) and litter quality of the component species, though the results are inconsistent among different studies (Hättenschwiler and Vitousek 2000; Hector et al. 2000; Hobbie et al. 1999; Hoorens et al. 2003). Most studies compared the observed with the expected mass loss rate based on the decomposition rates of single component litter; few of these studies explored the underlying mechanisms inducing the mixing effects (Hättenschwiler et al. 2005; Wardle et al. 1997). Even fewer studies attempted to separate the component litter species from the litter mixture to investigate how the identity of the neighboring litter species affected decomposition interactively (Barantal et al. 2011; Hoorens et al. 2010; Wardle et al. 2003).

In this study, we selected two dominant species, Stipa krylovii (Sk) and Astragalus galactites (Ag) with contrasting litter quality in terms of $\mathrm{N}$ content from a typical semiarid steppe ecosystem in Inner Mongolia, China to examine whether there were significant mixing effects on the decomposition of litter mixtures. In order to understand which factors determined the observed litter mixing effects, the two litter species in the litter mixture were mixed in three different treatments (thorough mixing, Sk on top of Ag, and Ag on top of Sk). We hypothesized that 1) the three mixing treatments would have different mixing effects as position could play an important role; 2) the high quality Ag litter would release nutrients while the low quality Sk litter would immobilize nutrients; and 3) the presence of Ag litter would facilitate the nutrient release whereas the Sk litter induce immobilization in the mixture. 


\section{Materials and methods}

\section{Study site}

The experimental site was located at a temperate steppe in Duolun County, Inner Mongolia ( $42^{\circ} 02^{\prime} \mathrm{N}, 116^{\circ} 17^{\prime} \mathrm{E}, 1324$ meters above sea level), China. This area is in a typical temperate zone characterized by a semiarid continental monsoon climate. Long-term mean annual precipitation is $385 \mathrm{~mm}$, and mean annual temperature is $2.1^{\circ} \mathrm{C}$ with monthly mean temperature ranging from $-17.5^{\circ} \mathrm{C}$ in January to $18.9^{\circ} \mathrm{C}$ in July. Annual rainfall is $198.5 \mathrm{~mm}$ in 2007, $314.4 \mathrm{~mm}$ in 2008, and $172.6 \mathrm{~mm}$ in 2009, and small daily rainfall events (0-2 mm) account for $67 \%, 50 \%$, and $68 \%$ of total rainfall from 2007 to 2009, respectively (Fig. 1). The sandy soil of the study site is classified as chestnut according to the Chinese classification, or Haplic Calcisols according to the Food and Agriculture Organization (FAO) classification. The surface $10 \mathrm{~cm}$ soil layer is slightly alkaline ( $\mathrm{pH}=7.2)$ and contains $20.4 \mathrm{~g} \mathrm{~kg}^{-1}$ total $\mathrm{C}, 1.63 \mathrm{~g}$ $\mathrm{kg}^{-1}$ total $\mathrm{N}$ with $10.35 \mathrm{mg} \mathrm{kg}^{-1}$ total available $\mathrm{N}$, and $0.31 \mathrm{~g} \mathrm{~kg}^{-1}$ total phosphorus (P) (Liu et al. 2010). Mean soil bulk density is $1.31 \mathrm{~g} \mathrm{~cm}^{-3}$.

\section{Experimental design}

The selected species in this study, Stipa krylovii (Sk) and Astragalus galactites (Ag), are two dominant species in this typical steppe ecosystem in Inner Mongolia grassland. S. krylovii is a perennial bunchgrasses, and A. galactites is a perennial forb and an important legume species in the studied grassland system (Yang et al. 2011). The two litter species have quite different chemical and physical properties. The initial $\mathrm{N}$ concentration of the litter of Ag is about four times of that of Sk, and the initial P concentration of Ag is also significantly higher than that of Sk (Table 1).

In late September 2006, the senescent leaf litters from the current year of the two species were collected, air-dried and placed in polyethylene litterbags $(15 \times 20 \mathrm{~cm}$, 
1mm mesh). Each bag was filled with $15 \mathrm{~g}$ litter either from a single litter species (Ag or Sk), or a 1:1 mixture of the two litter species. Two litter species were either mixed thoroughly (Sk-Ag) or separated by a polyethylene sheet $(0.20 \mathrm{~mm}$ in mesh size) in the litterbags. For the two mixing treatments with a divider, either Sk or Ag was placed on top of the other (Sk/Ag and $\mathrm{Ag} / \mathrm{Sk}$ ). In total there were five treatments: two single litter treatments (Ag and Sk) and three litter mixing treatments (Sk-Ag, Sk/Ag and Ag/Sk). The initial litter weight (15g air-dried litter) in each bag was chosen based on the following considerations: (1) experimental duration ( 3 years), (2) potential decomposition rate in this area, and (3) sufficient remaining mass for chemical analyses after decomposition. The choice of the litterbag size was constrained by the limited space among plant clumps in the studied community, i.e., it would be difficult to use litterbags larger than $15 \mathrm{~cm} \times 20 \mathrm{~cm}$.

On October 27 2006, 200 litterbags were deployed in five replicate plots, with 40 in each plot. Litterbags were retrieved after 162, 252, 341, 620, 706, 911, 991, and 1072 days, respectively, during the following three years. At each collection date, one set of litterbags, i.e., one litterbag of each single litter species and of each of the three mixing treatments from each replicate plot (25 total each time), was randomly collected, and then transported back to the laboratory.

In the laboratory, five sub-samples of each type of the original litter were oven-dried at $70^{\circ} \mathrm{C}$ for $48 \mathrm{~h}$ before initial deployment to determine the ratio of air-dried versus oven-dried mass. This ratio was used to calculate the initial oven-dried mass of each litterbag from the air-dried mass. After the litterbags were collected, extraneous matter such as in-growth plant materials and small animals were removed from the decomposing litter, when the mixture of Sk/Ag and Ag/Sk were separated by species. The soil mixed with the litter sample was rinsed off in cold 
water, and the litter was then oven-dried at $70^{\circ} \mathrm{C}$ for $48 \mathrm{~h}$ to determine remaining dry mass.

\section{Chemical analyses}

To determine the initial litter chemistry, total C, $\mathrm{N}$ and $\mathrm{P}$ of the five original non-decomposed sub-samples were measured. Only N and P concentrations were examined for litter samples harvested during decomposition. All the litter samples were ground using a ball mill (Retsch MM 400, Retsch GmbH \& Co KG, Haan, Germany), and passed through a No. 4 sieve. Total C content was determined using $\mathrm{H}_{2} \mathrm{SO}_{4}-\mathrm{K}_{2} \mathrm{Cr}_{2} \mathrm{O}_{7}$ oxidation method (Nelson and Sommers 1996), and total $\mathrm{N}$ concentrations with an Alpkem autoanalyzer (Kjektec System 1026 Distilling Unit, Sweden). After sub-samples were digested in the mixture of $\mathrm{H}_{2} \mathrm{SO}_{4}$ and $\mathrm{H}_{2} \mathrm{O}_{2}$, total $\mathrm{P}$ was measured using molybdenum blue colorimetric method at $880 \mathrm{~nm}$.

\section{Statistical analyses}

The expected percent mass remaining of each litter mixture (Sk-Ag, Sk/Ag and Ag/Sk) was calculated as:

Expected percent mass remaining (\%) $=\left[M_{1} /\left(M_{1}+M_{2}\right)\right] \times R_{1}+\left[M_{2} /\left(M_{1}+M_{2}\right)\right] \times R_{2}$ where $R_{1}, R_{2}$ are the percent remaining mass (\%) of the singly decomposed litter species 1 and 2, respectively, and $M_{1}$ and $M_{2}$ are the estimated initial dry mass of each litter species in the mixture (Hoorens et al. 2003).

The expected percent $\mathrm{N}$ and $\mathrm{P}$ mass remaining in the litter mixtures were determined similarly based on $\mathrm{N}$ and $\mathrm{P}$ concentrations of each single litter species at each collection date. Any significant deviation from expected values indicates an interactive effect, either positive or negative, between the mixing litter species.

Repeated measures ANOVA was used to test the significance of the overall differences between the observed and the expected percent mass remaining values and 
between different litter mixing treatments (i.e., Sk-Ag, Sk/Ag and Ag/Sk) across the whole decomposing period, where time was treated as within-subject factor. Repeated measures ANOVA was also used to test the differences of the mass loss and nutrient concentration of the same litter species placed at different positions (top or bottom) during the whole decomposing period. One-way ANOVA was used to test the nutrient concentration differences between the two positions in the litterbag at each collection date. The regressions between time and the ratios of the percent remaining mass of the top and bottom treatments of the same species were also conducted. The significant level of $\alpha=0.05$ was used. Data analyses were performed using SPSS (version 16.0).

\section{Results}

\section{Mass loss of single-component litter and the mixtures}

After 1072 days, an average of $74.3 \%$ of the initial mass of the singly decomposed $\mathrm{Ag}$ litter was lost, compared with a $48.7 \%$ loss of the single Sk litter (Fig. 2a).

Among the three types of litter mixing treatments, Sk-Ag had a significant negative mixing effect on mass loss $(P=0.031)$. The amount of the observed percent mass remaining of the Sk-Ag treatment was $42.8 \%$ compared with the expected value of $41.0 \%$ at the end of this study. Sk/Ag also had a significant negative mixing effect on the mass loss $(P<0.001)$, and the observed percent mass remaining was $45.1 \%$, higher than the expected value of $41.0 \%$. In contrast, Ag/Sk did not show significant mixing effect on the mass loss $(P>0.05)$ (Fig. 2b, Table 2).

Litter placed on the top, either Sk or Ag, decomposed much faster than that at the bottom. There were significant differences in the percent mass remaining between the top and the bottom positions for both Sk and Ag at all collection dates except the one at day 162 (Fig. 3a,b). The ratios between top and bottom percent remaining mass 
showed a significant exponential decrease with time for both Sk and Ag, and tended to level off at the end of this study $\left(r^{2} \mathrm{sk}=0.84, r_{\mathrm{Ag}}^{2}=0.69\right.$, Fig. 3a,b).

\section{Nutrient concentrations of the component litter species and their nutrient release patterns}

$\mathrm{N}$ concentration of the litter species placed on the top was much higher than that of the same species placed at the bottom for both Sk and Ag ( $P=0.011$ for Sk; $P<0.001$ for Ag, Table 3, Fig. 4a,b) during decomposition. However, results of one-way ANOVA showed that significant difference in $\mathrm{N}$ concentrations of the two positions for the Sk litter was found only at the last collection date (Fig. 4a), while significant difference was found for the Ag litter retrieved at day 252, 341, 706 and 991 (Fig. 4b). $\mathrm{N}$ concentrations of Sk in Sk/Ag and Ag/Sk showed a small decrease at the beginning, increased continuously afterwards, and decreased again when it approached the end of the observation period (Fig. 4a). N concentrations of Ag in Ag/Sk and Sk/Ag showed remarkably large fluctuations during the decomposition period although there was an overall increasing trend after a dip at the beginning (Fig. 4b). Because the two component species could not be separated from each other in the thorough mixture Sk-Ag, we were unable to investigate separately the change of $\mathrm{N}$ and $\mathrm{P}$ concentrations of each decomposing litter species in the mixture.

Repeated measures ANOVA showed that there was no overall difference in $\mathrm{P}$ concentrations between the top and the bottom positions for both species ( $P=0.535$ for Sk; $P=0.163$ for Ag, Table 3, Fig. 4c, d). In addition, there was no significant difference in $\mathrm{P}$ concentrations of the two positions for the Sk litter at any collection date (Fig. 4c, d). However, one-way ANOVA results showed that the P concentration of the Ag litter on the top was significantly higher than that of the Ag litter at the bottom collected at day 620, 706 and 911 (Fig. 4d). 
For both single decomposition and mixing treatments, there was a releasing phase for both $\mathrm{N}$ and $\mathrm{P}$ of the Ag litter. A leaching phase of $\mathrm{N}$ and $\mathrm{P}$ was found followed by immobilization and then a release phase for the Sk litter (Fig. 5a-d). When Sk decomposed with Ag, a stronger immobilization of $\mathrm{N}$ was found at both top and bottom positions (Fig. 5a, $P=0.006$ ). There was no significant difference in $\mathrm{P}$ release between the Sk litter decomposing singly and at the bottom position of the mixture, but the percent P remaining of the Sk litter at the upper position was significantly lower than the above two positions (Fig. 5b, $P=0.002$ ). For the Ag litter, the release of $\mathrm{N}$ was the fastest when Ag was placed above Sk. It became the slowest when Ag was placed below Sk (Fig. 5c, $P<0.001$ ). The release of P during the Ag litter decomposition showed similar pattern to that of $\mathrm{N}$ (Fig. 5d, $P<0.001$ ).

Neither Sk-Ag nor Ag/Sk showed a significant mixing effect on $\mathrm{N}$ release (Table 2, $P>0.05$ ). However, there was a negative effect of the $\mathrm{Sk} / \mathrm{Ag}$ mixture on $\mathrm{N}$ release (Table 2, $P<0.001$ ), which was indicated by the higher observed percent $\mathrm{N}$ remaining value compared to the expected value over the whole decomposing period. Overall, $\mathrm{N}$ of the litter in the three mixtures was continuously released throughout the whole study period (Fig. 5e). All three mixtures had an overall significantly positive mixing effect on P release (Table 2). In addition, $\mathrm{P}$ was released throughout the study period with the exception of a large increase in the percent remaining after first year's decomposition and a small increase for the last 200 days of decomposition (Fig. 5f).

\section{Discussion}

\section{Mass loss in the mixtures}

In natural terrestrial ecosystems, litter species in the litter layer usually decompose in mixtures rather than singly, and the decomposition of litter mixture may be either 
enhanced or retarded by the component litter species. Previous studies have indicated that there were mixing effects on the decomposition of different litter species in fen ecosystems (Hoorens et al. 2003), boreal forests (Nilsson et al. 1999), grasslands and agricultural systems (Wardle et al. 1997). In this study, consistent with our first hypothesis, there were different mixing effects for different mixing treatments. We found significant negative mixing effects on the mass loss of the Sk/Ag mixture, significant but weaker negative mixing effects on the mass loss of the Sk-Ag mixture, while no significant mixing effect on the mass loss of the Ag/Sk mixture (Table 2). We also found that the percent mass remaining was significantly different between the two mixing positions for both Sk and Ag after 162 days (Fig. 3). The ratios of percent mass remaining between the top and the bottom litter species, for both Sk and Ag, decreased exponentially with time but tended to level off later (Fig. 3 inset). The average difference of the eight collection dates showed that Sk in the Ag/Sk treatment was $5.4 \%$ higher in percent mass remaining than that of the single Sk, while Ag in the $\mathrm{Ag} / \mathrm{Sk}$ treatment was 5.0\% lower in percent mass remaining than that of the single Ag. This difference between the two component litter in the Ag/Sk treatment counterbalanced each other. However, Sk in the Sk/Ag treatment was 3.5\% lower in percent mass remaining than the single Sk, while Ag in this mixture was $12.1 \%$ higher than the single Ag, resulting in a lower overall mass loss in the Sk/Ag mixture. Therefore, the difference in mixing effects on mass loss in different litter mixtures might be a result of the change in mixing positions.

Studies have shown that litter quality and the environmental factors regulated mixing effects. Litter chemistry can influence the decomposition rates of the component litter species through the transfer of nutrients and secondary chemicals among different litter species. This movement of materials can simply be caused by 
leaching (Fyles and Fyles 1993; McArthur et al. 1994), and may also be mediated by the growth of fungi (McTiernan et al. 1997). Rainfall and soil moisture also play an important role in dryland decomposition (e.g., Wang et al. 2009; Yahdjian et al. 2006). The frequency of small rainfall events (less than $2 \mathrm{~mm}$ ) accounted for more than $50 \%$ of the total rainfall in this semi-arid steppe area over the three years of observation, and may induce little effects on $\mathrm{N}$ leaching from the top litter to the bottom litter. Under this situation, the rain water might rarely reach the bottom litter species, and might hardly produce sufficient moisture conditions for the decomposition of the bottom litter species. Wardle et al. (2003) found that positive mixing effect was largely caused by low quality component litter due to its contribution to enhancing the moisture status in the litter layer. Their study results, supported by others, also suggested that the changes in environmental conditions affected the progress of decomposition and litter-mixing effects (Gartner and Cardon 2006; Jonsson and Wardle 2008; Madritch and Cardinale 2007).

Mixing effect in this study could be affected by our specific litterbag design as the top and bottom layers of the two species were separated by a polyethylene barrier with $0.2 \mathrm{~mm}$ mesh size. This separation could lead to difference in moisture content of the top and the bottom litter as the upper litter might receive more water than the bottom litter when the amount of rainfall was small. At the same time, this was a full factorial experimental design, i.e., Ag/Sk treatment, Sk/Ag treatment, and thorough mixing (Sk-Ag). The same negative mixing effect was detected in both Sk/Ag and Sk-Ag treatments. Therefore, the effect of the experimental design on the mixing effects may not be significant.

Our results showed that the litter placed on the top, which received more rainfall and solar radiation, decomposed much more quickly at the early period than the same 
litter species placed at the bottom. Berg and Laskowski (2006) also showed that early stage mass loss could be stimulated by climatic factors and the availability of nutrients such as $\mathrm{N}$ and P. Since there was no difference in chemical concentrations between the two positions at the beginning of the decomposition, we concluded that the environmental factors might induce significant differences in mass loss between the two positions since the very beginning of the decomposition. Besides, the overall higher decomposition rate of the component species on the top could be mainly due to the faster mass loss at the early stage, as the effect of position seemed to level off at the later stage (Fig. 3 inset).

\section{Nutrient dynamics during decomposition}

Studies have shown a typical triphasic pattern for nutrient release during litter decomposition. However, not all three phases will occur during decomposition. For example, only phase III will occur in the decomposition of litter species with high nutrient concentration (Berg and Laskowski 2006; Prescott 2005). Sometimes, only phase II and III occur during the decomposition of nutrient-poor litter species.

The increase in $\mathrm{N}$ concentrations of the remaining litter during decomposition is common in most previous studies, and this has generally been interpreted as microbial immobilization. In this study, we also found that there was significant increase in $\mathrm{N}$ concentrations of both the Sk and the Ag litter (Fig. 4a,b). Fewer studies have shown that litter P concentrations also increase during litter decomposition as most studies only focused on N. Results from this study indicated that P concentrations of the Sk litter also increased throughout the decomposition (Fig. 4c). However, there was not

much net immobilization as the remaining P did not exceed the initial litter P content (Fig. 5b). According to some of the previous studies, the increase in P concentrations and percent remaining have also been interpreted as microbial immobilization, 
especially when the availability of P is high due to fertilization (Liu et al. 2006; McGroddy et al. 2004) or high P content in the co-existing litter (e.g., Ag in this study).

Our results showed that when Sk and Ag decomposed separately, the Ag litter generally released $\mathrm{N}$ and P over the three-year decomposition. The Sk litter, however, released $\mathrm{N}$ and $\mathrm{P}$ at the early stage of decomposition, followed by an immobilization period, and then released nutrients again (Fig. 5a-d). This generally agreed with our second hypothesis. Both litter species showed similar N and P release patterns regardless of their positions in the mixtures. When they were mixed, $\mathrm{N}$ was continuously released throughout the whole decomposition period regardless of the mixing treatments, which was similar to the pattern of individual Ag litter (Fig. 5c, e). The release pattern of $\mathrm{P}$ in the mixtures, on the other hand, was more similar to the pattern of individual Sk litter with short-term immobilization in the middle stage of decomposition (Fig. 5b, f). Therefore, the release of $\mathrm{N}$ from the mixtures during decomposition was primarily determined by the fast decomposing Ag litter while the release of P was largely determined by the slow decomposing Sk litter. In particular, when Ag litter was placed at the bottom of the litterbags, the decomposition of the Sk/Ag mixture was slowed down significantly, resulting in significant negative mixing effects on the $\mathrm{N}$ release. This also suggests that when the litter layer of a natural community has large amounts of Sk over Ag litter, high $\mathrm{N}$ retention will likely occur.

Although P was immobilized in the individual Sk litter (Fig. 5c) and in the mixtures (Fig. 5f) at the middle stage of decomposition, the immobilization in the mixture was not as strong as in the Sk litter of the single decomposition treatment (Fig. 5b). This indicates that the presence of the Ag litter during the Sk litter decomposition 
alleviated P limitation for microbial needs. Sk-Ag, Ag/Sk and Sk/Ag mixtures all had significant positive effects on P release (Table 2) although the mixing effects on mass loss were only found significantly negative for the Sk-Ag and the Sk/Ag mixtures, suggesting that the presence of Ag might stimulate P release of the Sk litter. This also partially confirmed our third hypothesis. Liu et al. (2006) found that the addition of $\mathrm{P}$ significantly accelerated the decomposition of Sk, indicating limitations of $\mathrm{P}$ in this area during litter decomposition. Therefore, mixing of different litter types may have different effects on the release of $\mathrm{N}$ and $\mathrm{P}$. Litter mixing had different non-additive effects on $\mathrm{N}$ and $\mathrm{P}$ dynamics during litter decomposition, which was also found by Ball et al. (2009). This was possibly due to nutrient limitations or different capacities of $\mathrm{N}$ and P uptake by microbial communities (Hobbie and Vitousek 2000).

In this typical semiarid steppe ecosystem, litter fall is a gradual process at the end of the growing season. Different litter species may be layered randomly either on the top or at the bottom position to form different types of litter mixtures, and this was generally neglected in most studies on the decomposition of litter mixtures. Gartner and Cardon (2004) proposed that the potential for interaction among different litter species may be determined by how leaves are mixed in litterbags (i.e., whether the leaves are layered in the order of the leaf fall or are thoroughly mixed). The results from this study clearly showed that there were different mixing effects with different mixing treatments.

\section{Conclusions}

Based on a three-year decomposition experiment, this study demonstrated that different mixing treatments of litter species had different mixing effects on the mass loss and the release of $\mathrm{N}$. All three mixing treatments had positive effects on the 
release of $\mathrm{P}$. We found that the release of $\mathrm{N}$ from the mixtures was primarily determined by the fast decomposing Ag litter while the release of P was largely determined by the slow decomposing Sk litter. The fast decomposition at the early stage more or less determines the overall rate of the mass loss. Based on these results, we think it is necessary to consider the litter placement in the litter layer when evaluating the decomposition of the mixtures and the cycling of nutrients. Our results also suggest that different mixing positions of litter species will result in different non-additive effects on the release of nutrients such as $\mathrm{N}$ and $\mathrm{P}$, which may further increase the heterogeneity of the nutrient distribution pattern in the studied steppe ecosystem.

\section{Acknowledgements}

The authors would like to thank Ang Li and Jianyang Xia for their constructive comments on an earlier version of this manuscript. We are also extremely grateful for the two anonymous reviewers and the section editor Tim Moore for their constructive comments. This study was financially supported by the National Basic Research Program of China (2009CB421102) and the National Natural Science Foundation of China (41073056). We also thank the Duolun Restoration Ecology Research Station for permission to access the study site and for technical assistance.

\section{References}

Aerts R 1997 Climate, leaf litter chemistry and leaf litter decomposition in terrestrial ecosystems: A triangular relationship. Oikos 79, 439-449.

Austin A T and Vitousek P M 2000 Precipitation, decomposition and litter decomposability of Metrosideros polymorpha in native forests on Hawai'i. 
Journal of Ecology 88, 129-138.

Austin A T and Vivanco L 2006 Plant litter decomposition in a semi-arid ecosystem controlled by photodegradation. Nature 442, 555-558.

Ball B A, Bradford M A and Hunter M D 2009 Nitrogen and Phosphorus Release from Mixed Litter Layers is Lower than Predicted from Single Species Decay. Ecosystems 12, 87-100.

Barantal S, Roy J, Fromin N, Schimann H and Hättenschwiler S 2011 Long-term presence of tree species but not chemical diversity affect litter mixture effects on decomposition in a neotropical rainforest. Oecologia 167, 241-252.

Berg B and Ekbohm G 1991 Litter mass-loss rates and decomposition patterns in some needle and leaf litter types - long-term decomposition in a Scots pine forest . VII. Canadian Journal of Botany 69, 1449-1456.

Berg B and Laskowski R 2006 Litter decomposition: a guide to carbon and nutrient turnover. Elsevier Academic Press, San Diego. pp. 102-183.

Bradford M A, Tordoff G M, Eggers T, Jones T H and Newington J E 2002 Microbiota, fauna, and mesh size interactions in litter decomposition. Oikos 99, 317-323.

Daniel O and Anderson J M 1992 Microbial biomass and activity in contrasting soil materials after passage through the gut of the earthworm Lumbricus rubellus hoffmeister. Soil Biology and Biochemistry 24, 465-470.

Dent D H, Bagchi R, Robinson D, Majalap-Lee N and Burslem D F R P 2006 Nutrient fluxes via litterfall and leaf litter decomposition vary across a gradient of soil nutrient supply in a lowland tropical rain forest. Plant and Soil 288, 197-215.

Fyles J W and Fyles I H 1993 Interaction of Douglas-fir with red alder and salal 
foliage litter during decomposition. Canadian Journal of Forest Research 23, $358-361$.

Gartner T B and Cardon Z G 2004 Decomposition dynamics in mixed-species leaf litter. Oikos 104, 230-246.

Gartner T B and Cardon Z G 2006 Site of leaf origin affects how mixed litter decomposes. Soil Biology \& Biochemistry 38, 2307-2317.

Hättenschwiler S, Tiunov A V and Scheu S 2005 Biodiversity and litter decomposition interrestrial ecosystems. Annual Review of Ecology Evolution and Systematics 36, 191-218.

Hättenschwiler S and Vitousek P M 2000 The role of polyphenols in terrestrial ecosystem nutrient cycling. Trends in Ecology \& Evolution 15, 238-243.

Hector A, Beale A J, Minns A, Otway S J and Lawton J H 2000 Consequences of the reduction of plant diversity for litter decomposition: effects through litter quality and microenvironment. Oikos 90, 357-371.

Hobbie S E, Shevtsova A and Chapin F S 1999 Plant responses to species removal and experimental warming in Alaskan tussock tundra. Oikos 84, 417-434.

Hobbie S E and Vitousek P M 2000 Nutrient limitation of decomposition in Hawaiian forests. Ecology 81, 1867-1877.

Hoorens B, Aerts R and Stroetenga M 2003 Does initial litter chemistry explain litter mixture effects on decomposition? Oecologia 137, 578-586.

Hoorens B, Coomes D and Aerts R 2010 Neighbour identity hardly affects litter-mixture effects on decomposition rates of New Zealand forest species. Oecologia 162, 479-489.

Jonsson M and Wardle D A 2008 Context dependency of litter-mixing effects on decomposition and nutrient release across a long-term chronosequence. Oikos 
117, 1674-1682.

Liu P, Huang J, Han X, Sun O J and Zhou Z 2006 Differential responses of litter decomposition to increased soil nutrients and water between two contrasting grassland plant species of Inner Mongolia, China. Applied Soil Ecology 34, 266-275.

Liu P, Huang J, Sun O J and Han X 2010 Litter decomposition and nutrient release as affected by soil nitrogen availability and litter quality in a semiarid grassland ecosystem. Oecologia 162, 771-780.

Madritch M D and Cardinale B J 2007 Impacts of tree species diversity on litter decomposition in northern temperate forests of Wisconsin, USA: a multi-site experiment along a latitudinal gradient. Plant and Soil 292, 147-159.

McArthur J V, Aho J M, Rader R B and Mills G L 1994 Interspecific leaf interactions during decomposition in aquatic and floodplain ecosystems. Journal of the North American Benthological Society 13, 57-67.

McGroddy M E, Silver W L and Oliveira R C d, Jr. 2004 The Effect of Phosphorus Availability on Decomposition Dynamics in a Seasonal Lowland Amazonian Forest. Ecosystems 7, 172-179.

McTiernan K B, Ineson P and Coward P A 1997 Respiration and nutrient release from tree leaf litter mixtures. Oikos 78, 527-538.

Moore T R, Bubier J L and Bledzki L k 2007 Litter decomposition in temperate peatland ecosystems: The effect of substrate and site. Ecosystems 10, 949-963.

Nelson D and Sommers L 1996 Total carbon, organic carbon, and organic matter. In Methods of soil analysis. Part 3, Chemical methods. Eds. D L Sparks, A L Page, P A Helmke, R H Loeppert, M A Soltanpour, M A Tabatabai, C T Johnston and M E Sumner. pp 961-1010. Soil Science Society of America, 
American Society of Agronomy, Madison.

Nilsson M C, Wardle D A and Dahlberg A 1999 Effects of plant litter species composition and diversity on the boreal forest plant-soil system. Oikos 86, $16-26$.

Prescott C 2005 Decomposition and mineralization of nutrients from litter and humus. In Nutrient acquisition by plants. Ed. H BassiriRad. pp 15-41. Springer-Verlag, Berlin.

Swift M, Heal O and Anderson J 1979 Decomposition in terrestrial ecosystems. University of California Press, Los Angeles.

Throop H L and Archer S R 2009 Resolving the dryland decomposition conundrum: some new perspectives on potential drivers. In Progress in Botany. Eds. U Lüttge, W Beyschlag, B Büdel and D Francis. pp 171-194. Springer Berlin Heidelberg.

Vivanco L and Austin A T 2006 Intrinsic effects of species on leaf litter and root decomposition: a comparison of temperate grasses from North and South America. Oecologia 150, 97-107.

Wang L, D’Odorico P, Manzoni S, Porporato A and Macko S 2009 Soil carbon and nitrogen dynamics in southern African savannas: the effect of vegetation-induced patch-scale heterogeneities and large scale rainfall gradients. Climatic Change 94, 63-76.

Wardle D A, Bonner K I and Nicholson K S 1997 Biodiversity and plant litter: Experimental evidence which does not support the view that enhanced species richness improves ecosystem function. Oikos 79, 247-258.

Wardle D A, Nilsson M C, Zackrisson O and Gallet C 2003 Determinants of litter mixing effects in a Swedish boreal forest. Soil Biology \& Biochemistry 35, 
827-835.

Yahdjian L, Sala O and Austin A 2006 Differential Controls of Water Input on Litter Decomposition and Nitrogen Dynamics in the Patagonian Steppe. Ecosystems 9, 128-141.

Yang H, Wu M, Liu W, Zhang Z, Zhang N and Wan S 2011 Community structure and composition in response to climate change in a temperate steppe. Global Change Biology 17, 452-465. 
Table 1 Initial litter chemistry for the two grassland plant species, Stipa krylovii (Sk) and Astragalus galactites (Ag), data are means \pm SE $(n=5)$. Different superscript letters in a column indicate significant difference between the two species.

\begin{tabular}{lllllll}
\hline Species & $\mathrm{N}(\mathrm{mg} / \mathrm{g})$ & $\mathrm{P}(\mathrm{mg} / \mathrm{g})$ & $\mathrm{C}(\mathrm{mg} / \mathrm{g})$ & $\mathrm{N} / \mathrm{P}$ & $\mathrm{C} / \mathrm{N}$ & $\mathrm{C} / \mathrm{P}$ \\
\hline Sk & $5.54 \pm 0.29^{\mathrm{b}}$ & $0.96 \pm 0.03^{\mathrm{b}}$ & $407.46 \pm 6.23^{\mathrm{b}}$ & $5.78 \pm 0.28^{\mathrm{b}}$ & $74.40 \pm 4.42^{\mathrm{a}}$ & $425.75 \pm 16.12^{\mathrm{a}}$ \\
$\mathrm{Ag}$ & $21.44 \pm 0.19^{\mathrm{a}}$ & $1.59 \pm 0.01^{\mathrm{a}}$ & $438.19 \pm 5.80^{\mathrm{a}}$ & $13.46 \pm 0.07^{\mathrm{a}}$ & $20.44 \pm 0.21^{\mathrm{b}}$ & $275.20 \pm 3.73^{\mathrm{b}}$ \\
\hline
\end{tabular}


Table 2 Summary of the repeated measures ANOVA results for the difference between the expected and observed values of percent mass remaining (\%), percent $\mathrm{N}$ remaining (\%) and percent P remaining (\%) in the three mixtures. Sk, Stipa krylovii; Ag, Astragalus galactites.

\begin{tabular}{|c|c|c|c|c|c|c|c|}
\hline & & \multicolumn{2}{|c|}{ Sk-Ag } & \multicolumn{2}{|c|}{ Ag/Sk } & \multicolumn{2}{|c|}{ Sk/Ag } \\
\hline & & $F$ & $P$ & $\bar{F}$ & $P$ & $\bar{F}$ & $P$ \\
\hline \multirow{3}{*}{ Percent Mass remaining (\%) } & Mixing (M) & 6.8 & 0.031 & 0.1 & 0.739 & 76.6 & $<0.001$ \\
\hline & Day (D) & 1009.0 & $<0.001$ & 867.2 & $<0.001$ & 756.7 & $<0.001$ \\
\hline & $M \times D$ & 0.3 & 0.935 & 1.5 & 0.234 & 2.6 & 0.027 \\
\hline \multirow{3}{*}{ Percent N remaining (\%) } & Mixing (M) & 0.0 & 0.992 & 0.3 & 0.576 & 78.8 & $<0.001$ \\
\hline & Day (D) & 38.9 & $<0.001$ & 125.3 & $<0.001$ & 98.6 & $<0.001$ \\
\hline & $\mathrm{M} \times \mathrm{D}$ & 0.5 & 0.666 & 0.8 & 0.598 & 1.9 & 0.090 \\
\hline \multirow[t]{3}{*}{ Percent P remaining (\%) } & Mixing (M) & 17.9 & 0.003 & 8.4 & 0.020 & 7.0 & 0.030 \\
\hline & Day (D) & 34.5 & $<0.001$ & 39.2 & $<0.001$ & 38.8 & $<0.001$ \\
\hline & $\mathrm{M} \times \mathrm{D}$ & 6.7 & $<0.001$ & 2.2 & 0.044 & 2.8 & 0.025 \\
\hline
\end{tabular}

Notes: Sk-Ag means a thorough mixing, Ag/Sk means Ag on the top, Sk/Ag means Sk on the top. 
Table 3 Summary of the repeated measure ANOVA results for the difference between $\mathrm{N}$ and $\mathrm{P}$ concentration of the same species under different positions during decomposition. Sk, Stipa krylovii; Ag, Astragalus galactites.

\begin{tabular}{lllllll}
\hline \multirow{2}{*}{ Species } & & \multicolumn{2}{l}{$\mathrm{N}(\mathrm{mg} / \mathrm{g})$} & & \multicolumn{2}{c}{$\mathrm{P}(\mathrm{mg} / \mathrm{g})$} \\
\cline { 3 - 4 } \cline { 6 - 7 } & & $F$ & $P$ & & $F$ & $P$ \\
\hline \multirow{2}{*}{ Ag } & Position (P) & 137.217 & $<\mathbf{0 . 0 0 1}$ & 2.359 & 0.163 \\
& Day (D) & 34.581 & $<\mathbf{0 . 0 0 1}$ & 5.035 & $\mathbf{0 . 0 0 3}$ \\
& P $\times$ D & 2.55 & $\mathbf{0 . 0 4 2}$ & 0.543 & 0.706 \\
Sk & Position (P) & 10.705 & $\mathbf{0 . 0 1 1}$ & 0.42 & 0.535 \\
& Day (D) & 35.658 & $<\mathbf{0 . 0 0 1}$ & 23.087 & $<\mathbf{0 . 0 0 1}$ \\
& P $\times$ D & 0.99 & 0.448 & 0.541 & 0.787 \\
\hline
\end{tabular}




\section{Figure legends}

Fig. 1 The frequency distribution of the daily precipitation amount and the monthly precipitation distribution (inset) during the three years (2007-2009).

Fig. 2 Percent mass remaining (\% of initial litter mass) in decomposition of Sk (Stipa krylovii) and Ag (Astragalus galactites) in single decomposition and mixtures during decomposition. a, decomposing singly; b, decomposing in mixtures

Fig. 3 Percent mass remaining of the component species in the two mixing treatments.

a, Sk from Sk/Ag (means Sk on the top) and Ag/Sk (means Ag on the top), respectively; b, Ag from Ag/Sk and Sk/Ag, respectively. Inset figure in each panel indicates the regressions between time and the ratios of the percent mass remaining of the top and bottom treatments. All the data are mean \pm 1 SE, n =5. Sk, Stipa krylovii; Ag, Astragalus galactites.

Fig. 4 The N and P concentration of the component species Sk and Ag in the litter mixture across the decomposition period (mg.g $\left.{ }^{-1}\right), \mathbf{a}, \mathrm{N}$ concentration of Sk; $\mathbf{b}, \mathrm{N}$ concentration of Ag; c, P concentration of Sk; d, P concentration of Ag. Data are means $\pm 1 \mathrm{SE}, \mathrm{n}=5 . *=P<0.05 ; * *=P<0.01 ; * * *=P<0.001$. Sk, Stipa krylovii; Ag, Astragalus galactites.

Fig. 5 The nutrient dynamics (\% of initial values) in the Sk and the Ag single decomposition and the three mixing treatments. a, b, Percent $\mathrm{N}$ and $\mathrm{P}$ remaining of the Sk litter decomposing in single decomposition and in mixtures with Ag; c, d, Percent $\mathrm{N}$ and $\mathrm{P}$ remaining of the Ag litter decomposing in single decomposition and mixtures with Sk. e, f, Percent $\mathrm{N}$ and $\mathrm{P}$ remaining of the observed and the expected values of the mixing litter. Values are mean \pm 1 SE, $n=5$. Sk, Stipa krylovii; Ag, Astragalus galactites. 
Fig. 1

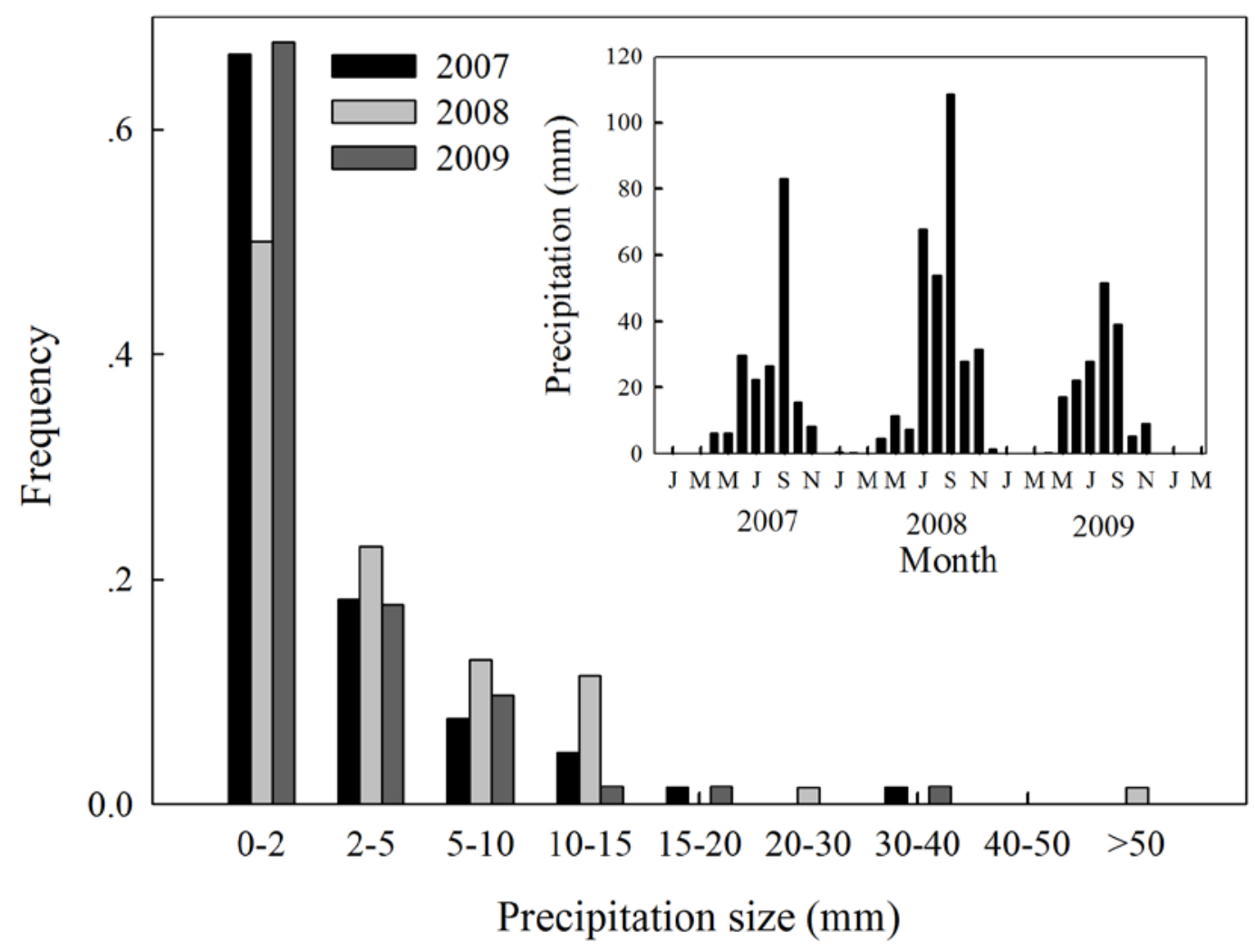


Fig. 2

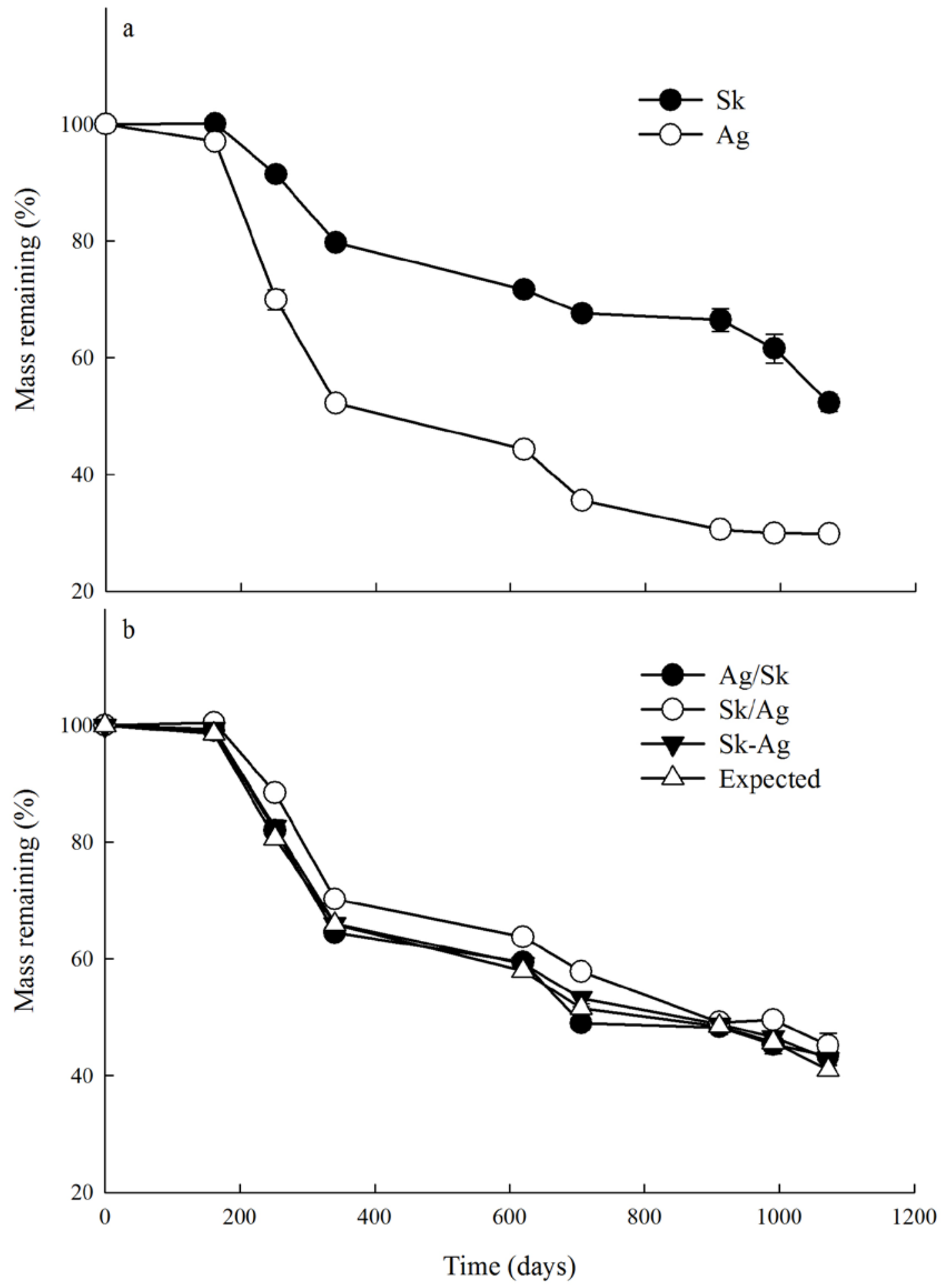


Fig. 3
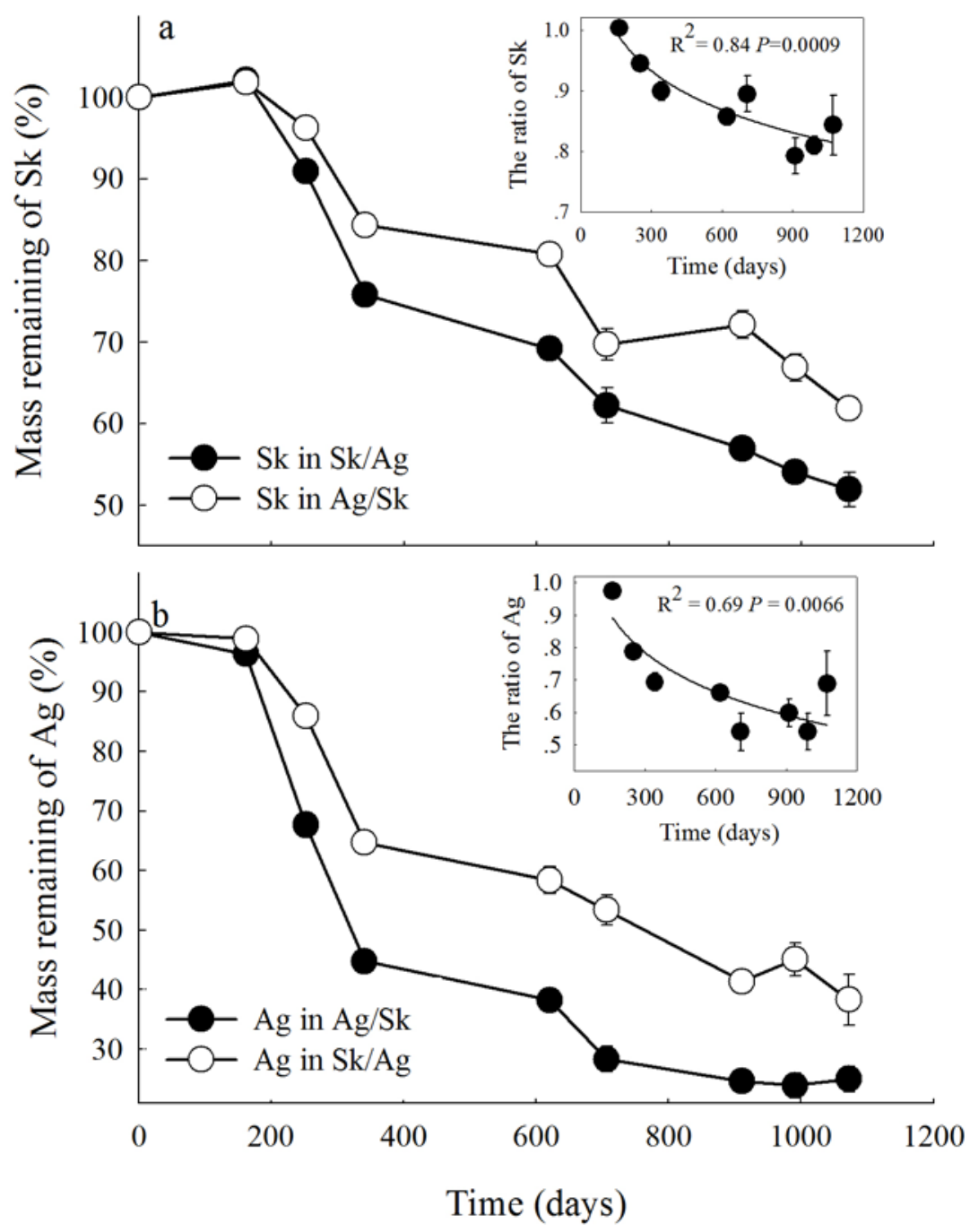
Fig. 4

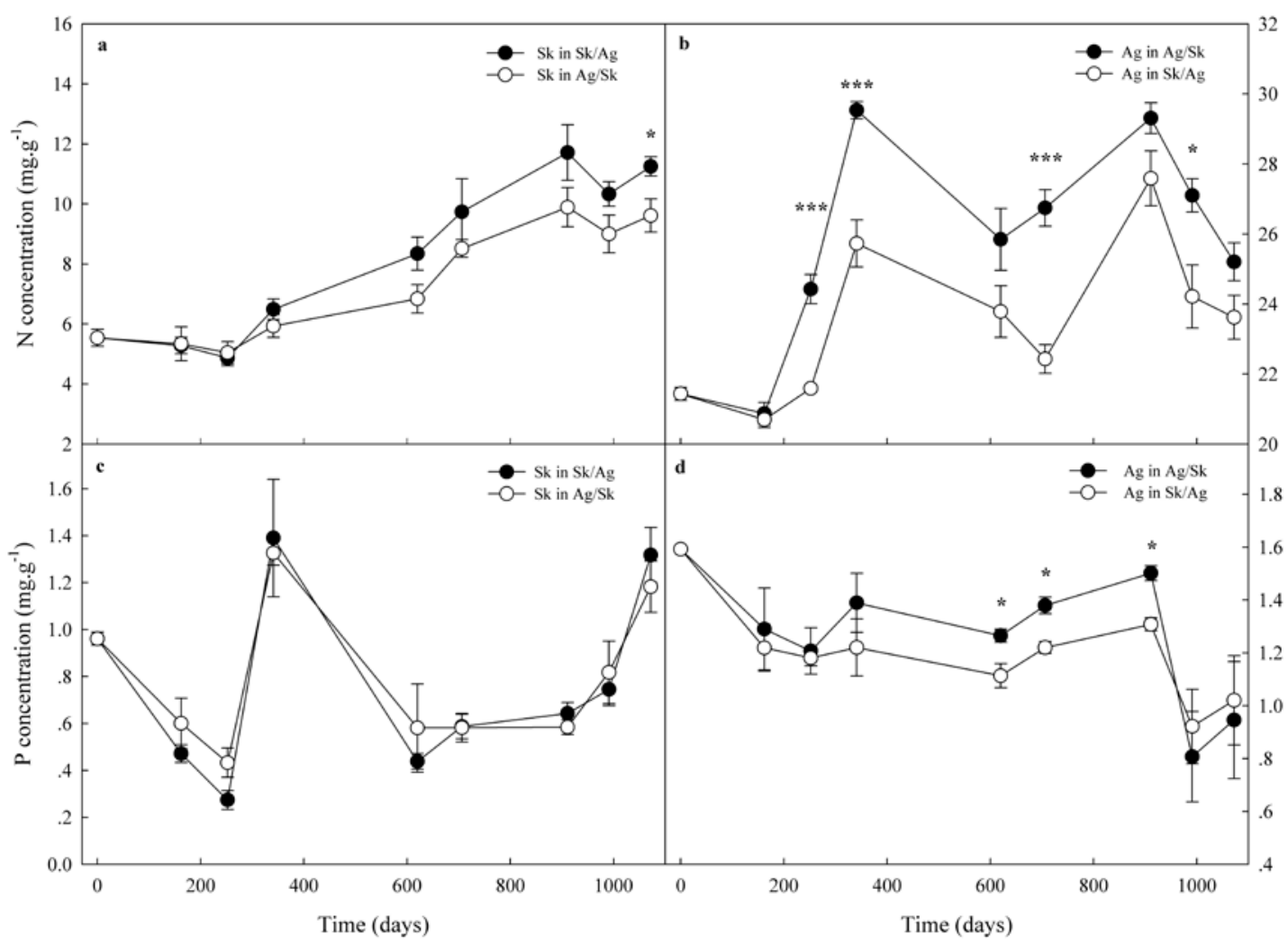


Fig. 5

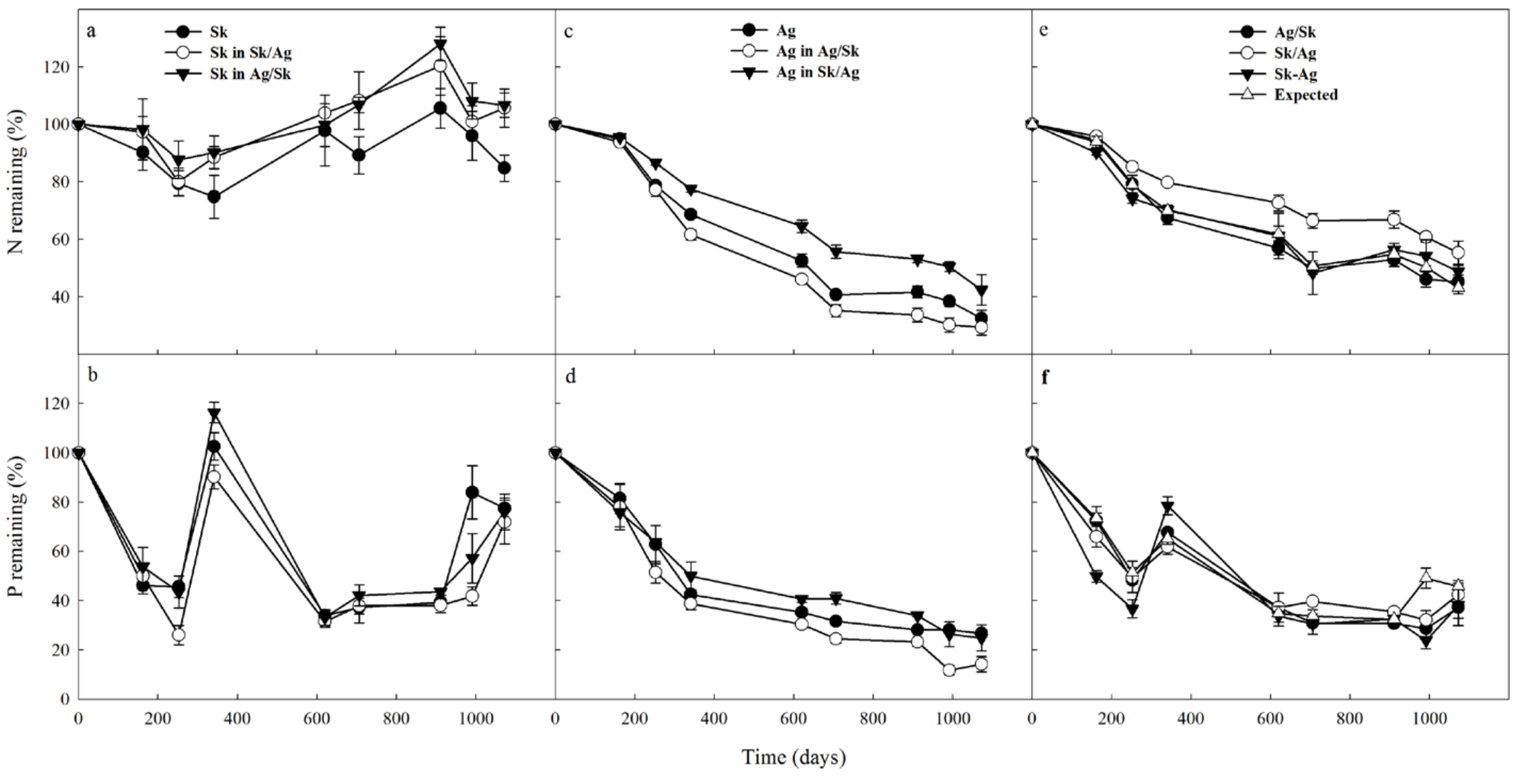

